\title{
Speciation of cesium adsorbed on tree tissues using EXAFS
}

\author{
KAZUYA TANAKA ${ }^{1}$, TSUTOMU KANASASHI ${ }^{2}$, CHISATO \\ TAKENAKA $^{3}$ AND YOSHIO TAKAHASHI ${ }^{4}$ \\ ${ }^{1}$ Japan Atomic Energy Agency, tanaka.kazuya@jaea.go.jp \\ ${ }^{2}$ Fukushima University, kogunkandori@yahoo.co.jp \\ ${ }^{3}$ Nagoya University, chisato@agr.nagoya-u.ac.jp \\ ${ }^{4}$ The University of Tokyo, ytakaha@eps.s.u-tokyo.ac.jp
}

Large amounts of radiocesium were released into the environemnt by the Fukushima Daiichi Nuclear Power Plant (FDNPP) accident in Japan. FDNPP-derived radiocesium was dispersed extensively through the air and deposited on land surface as well as the Pacific Ocean. About $70 \%$ of Fukushima Prefecture is occupied by forests, which were contaminated by the FDNPP-derived radiocesium. In this study, we investigated local coordination structure of Cs adsorbed on tree tissues to understand translocation and distribution of radiocesium uptaken into bodies of tree in forest systems.

We collected tree samples of the four species, Cryptomeria japonica, Pinus densiflora, Quercus serrata and Eleutherococcus sciadophylloides, which are representatives of evergreen and deciduous broad-leaved trees in Fukushima. Each tree sample of $C$. japonica and $P$. densiflora was divided into fragments of bark, sapwood, heartwood, needle and branch, while Q. serrata and E. sciadophylloides were cut into fragments of bark, sapwood and heartwood. Then, Cs-doped samples for respective parts were prepared for Cs LIII-edge EXAFS measurement using $1 \mathrm{M} \mathrm{CsCl}$ solution.

All the parts of the four tree species showed a similar frequency of EXAFS oscillation in $\mathrm{k}^{3}$-weighted $\chi(\mathrm{k})$ function. Furthermore, the Cs-adsorbed tree samples showed similar EXAFS oscillations to Cs-adsorbed cellulose and $50 \mathrm{mM}$ $\mathrm{CsCl}$ solution. The corresponding radial structural function (RSF) of the $50 \mathrm{mM} \mathrm{CsCl}$ solution indicated a single peak occurring at $\mathrm{R}+\Delta \mathrm{R}=2.4 \AA$, originating from scattering between $\mathrm{Cs}$ and $\mathrm{O}$ atoms of water molecules. Similarly, the Cs adsorbed tree and cellulose samples showed the only Cs$\mathrm{O}$ shell in RSFs, and no further shells were observed at a higher $\mathrm{R}+\Delta \mathrm{R}$. The EXAFS analysis suggests that Cs was adsorbed as an outer-sphere complex. If Cs was adsorbed as an inner-sphere complex to binding sites of cellulose, lignin and hemicellulose in tree tissues, second shell from Cs-C scattering would had been observed.

The formation of an outer-sphere complex indicates that Cs would be relatively mobile form in body of tree. Field researchers reported translocation of FDNPP-derived radiocesium in forest systems. The analytical result of EXAFS spectra is consistent with field observations. 